\title{
Dialectical Sculptural Experimentations of Postmodern Sculpture in Ghanaian Context
}

\author{
Theophilus Kwesi Mensah (Phd) \\ School of Creative Arts, Department of Art Education, University of Education, Winneba. P. O. Box 25, \\ Winneba - Ghana \\ Michael Manu-Kobia \\ School of Creative Arts, Department of Art Education, University of Education, Winneba. P. O. Box 25, \\ Winneba - Ghana \\ Agbeyewornu Kofi Kemevor (Phd) \\ School of Creative Arts. University of Education, Winneba. P. O. Box 25, Winneba - Ghana
}

\begin{abstract}
Commemorative and allegorical sculptures are very important constituents in the spatial, temporal and spatiotemporal art forms of any given community or people. This is because, not only are they symbolic, they also represent important landmarks in the history of the people. Constricting formal configuration of commemorative narratives in Ghana is the neoclassical concept of the monument which is heavily modelled on an "idealist myth" (Krauss, 1981,) However exhuming medieval spatial metaphors, this paper expounds how pole ideologies in history Vis a Vis current thought have informed and thus negotiated and expanded the frontiers of formal aesthetic dialogues. Attention will be drawn to the oversubscribed 'idealist' ideals (like frontality, the figure, the pedestal and preference for the noble media like stone, wood, bronze ivory cement etc.) in the expressing of commemorative sculpture in Ghana as if it were the modus- operandi. Finally, a research work which used 'Fante' proverbs as its principal reference point is introduced not to only seek a defiance of these academic conventions but also explore the vernacular qualities of found media (ready- made) specifically scrap metals which have had former lives before and thus fraught with in context meaning to a new aesthetic end.
\end{abstract}

Keywords: narratives, readymade, hybridity, dualism, dialectic, idealism, materialism, minimalism.

DOI: $10.7176 / \mathrm{ADS} / 83-04$

Publication date:July $31^{\text {st }} 2020$

\section{INTRODUCTION}

Art historians and critics over the years have wondered and asked about the nature of sculpture and how this unique experience of art could be defined. If in this $21^{\text {st }}$ century the same question is being asked, it is because this unique art form of sculpture keeps on taken forms which its contemporary viewer finds difficult to assimilate because of his pre-conceived ideas of what should constitute a work of sculpture. Critics have always argued whether there is a difference between a temporal event and a static object and, if so, what impact this difference has on the construction of the art forms concerned with them.

By the 1930s this sense of an expected antagonism between an art of time and an art of space had become a basic starting point from which to assess the unique accomplishment of sculpture (Krauss 1981). Since then rather amazing things have come not only to contend the traditional landmarks of sculpture but to also reshape it. Sculpture thus has ceased to become a stasis but an organic entity with a life of its own.

To Rosalind E. Krauss the essence of sculpture [or the monument] is not its "simulated quality" but its ability to encapsulate an ideology which by medieval standards, relief yielded itself as the most suitable vehicle of communication. (Figure 1) 


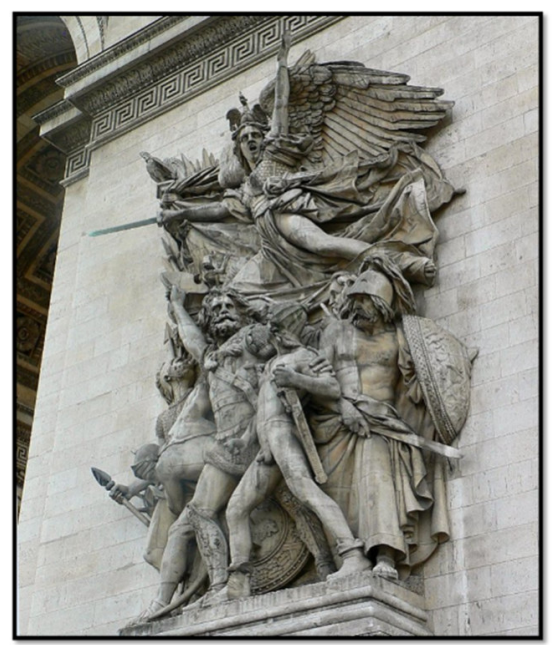

Figure 1: Francois Rude (La Marseillaise, 1833-36.stone, 504"x312", Arch of triumph, Paris.) Source: http://graphics8.nytimes.com/images/2005/10/13/arts/eskin.583.1.jpg.

Accessed on January 9th, 2009.

It was therefore to realize the above epitomized formal effect and viewing experience why the neoclassical sculptors delineated "the human body through multiple views" manipulating the "figures in pairs and in threes, so that the front view of one figure would be available simultaneously with the back view of its mate" (as in Canova' Grasses), (fig2) in which the "presentation arranges the bodies along a single, frontal plane, so that it is legible at a glance" (Krauss1981).

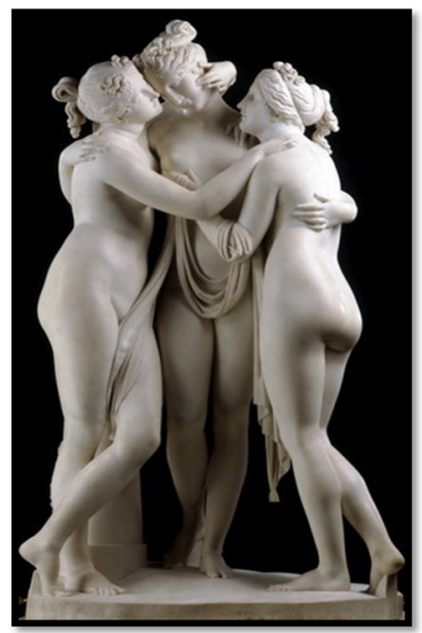

Figure 2: Antonio Canova: The Three Graces, 1813. Marble. Source:

http://www.creativelydifferentblinds.com/VAImagesVASculpture/TheThreeGracesntonioCanova2.aspx. Accessed 09/12/ 2008.

Aimed at positing an epitomized composition, this convention did not only inform the productions of a great number of sculptures during the late $18^{\text {th }}$ and early $19^{\text {th }}$ century it still informs the production of sculptures in modern day Ghana (figures3a- 3d). 


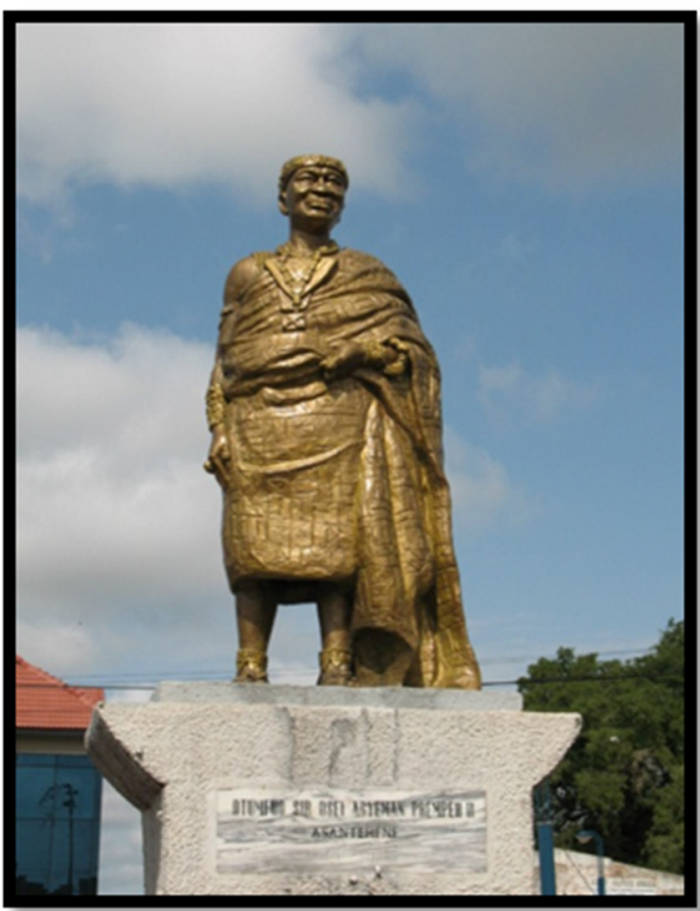

Figure 3a: Prempeh II Ashanti king, size (life size). Location: Adum, Kumasi

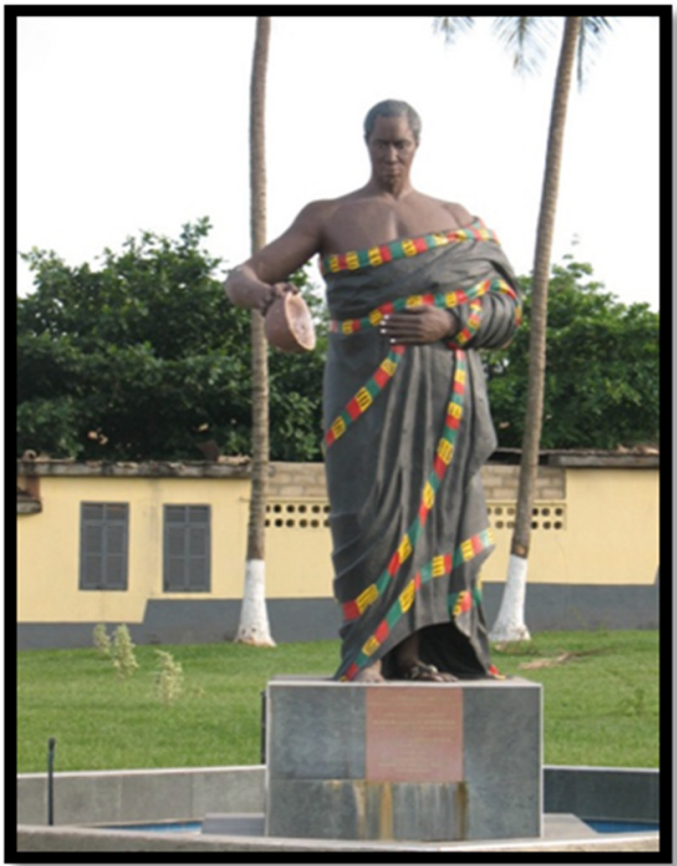

Figure 3c: Major Kobina size (heroic size)

Location: Wawase, Fantenewtown, Kumasi

However, the convention degenerates, resulting rather in a formulaic configuration of figures around a single idealized vertical axis. Dictating not only a hackneyed composition (with only a single focal point), but also the convention again establishes a uniocular relationship (between sculpture- viewer), offering the viewer at a single sweeping glance (an idealized locos) a tailored omniscient view of the sculpture.

\section{BETWEEN IDEOLOGIES}

Art critics and historians have aforementioned that, the antiquity of sculpture had an out- and- out snapping point during the twentieth century. This is because it was during this period that a lot of the degenerated teleological and methodic modes of expression from the medieval times like (frontality, the pedestal, and the human figure) 
('idealism exponent') which over the years had been projected as the most ideal forms of expression, were cast aside.

Until this period the pedestal which was seen as the most ideal means of affixing narratives had enjoyed a dual status. On one hand, it created a transition between sculpture and the material world. On the other hand, it contained within its self a split, a division between the two. This ambiguous nature of the pedestal gave rise to a metaphoric interpretation of the narratives by the passive on looker because the narrative now stood 'illusionistitcally', outside his tangible reality. When the pedestal lost its position as the most ideal support on which to affix the narrative, a totally new conception of sculpture came about. At this point on sculpture ceased to be just a narrative which embodied an ideology or a memory in a metaphorical way, on the basis of similarity. From then on sculpture became part of the same space of the passive on looker.

This new breaking point in history launched two new routes of the narrative, on one hand by been placed in the material world of the on looker, the viewers experience in time and space thus becomes an essential part of the object of modern sculpture as evinced in Richard Serra's work 'matter of time' (fig4) and Bruce Nauman's 'corridor'(fig5). These works and a host of other works were an attack on the conventions of sculpture as they had been maintained throughout the centuries. On the other hand, by being freed from the pedestal the narrative is able to ascend into the idealistic world of absolute form which was key to the 'Formalist' as clearly exhibited in Constantin Brancusi's work 'bird in space' (fig6).

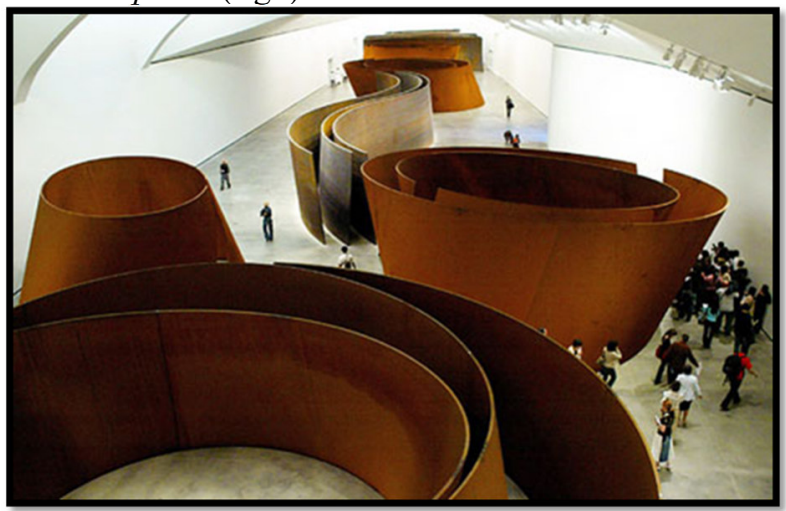

Figure 4: Richard Serra: A Matter of Time.

Source: http://www.jstor.org/stable/1425398. Assessed: 12/11/2008.

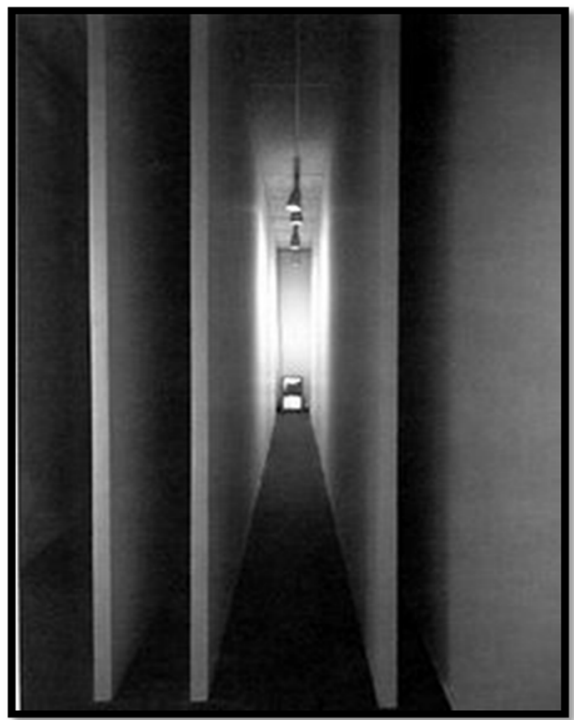

Figure 5: Bruce Nauman, Live-Taped Video Corridor, 1970, video installation at the Whitney Museum of American Art, New York.

Source: http://www.jstor.org/stable/777705. Assessed: 14/04/2009. 


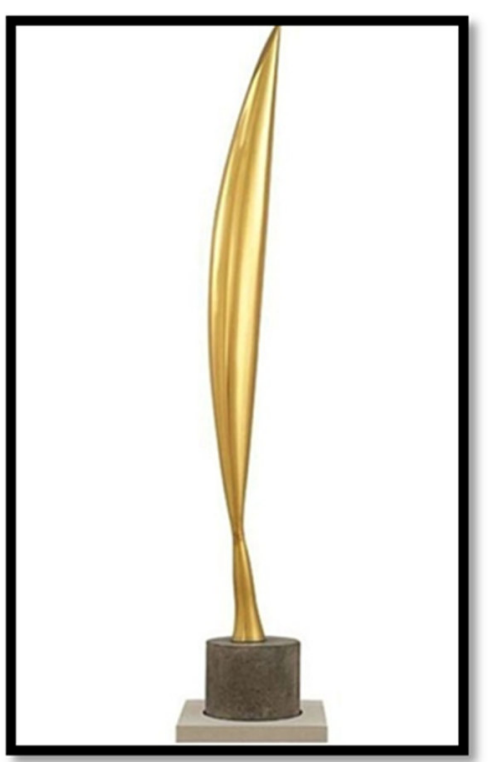

Figure 6: Constantin Brancusi: Bird in Space, Bronze.

Source: http://www.chess-theory.com/images5/22721_constantin_brancusi.jpg.

\section{READY MADES IN SCULPTURE}

Found media, indicates the use of objects which have had former lives before but have now been incorporated into art. In other words they are objects which were not originally designed for the purpose of art. They come in either, utilitarian, manufactured items or things which occur in nature.

Pablo picasso and kurt schnitter were among the early protagonists of the use of found media (ready mades) in art but the artist who shocked the art world with readymade art was Marcel Duchamp with his famous display of a ceramic urinal (fountain) (figure 7) in 1917. The Fountain made a lot of waves on the art scene because all that Duchamp did was to exhibit this urinal bowl and declared it a work of art.

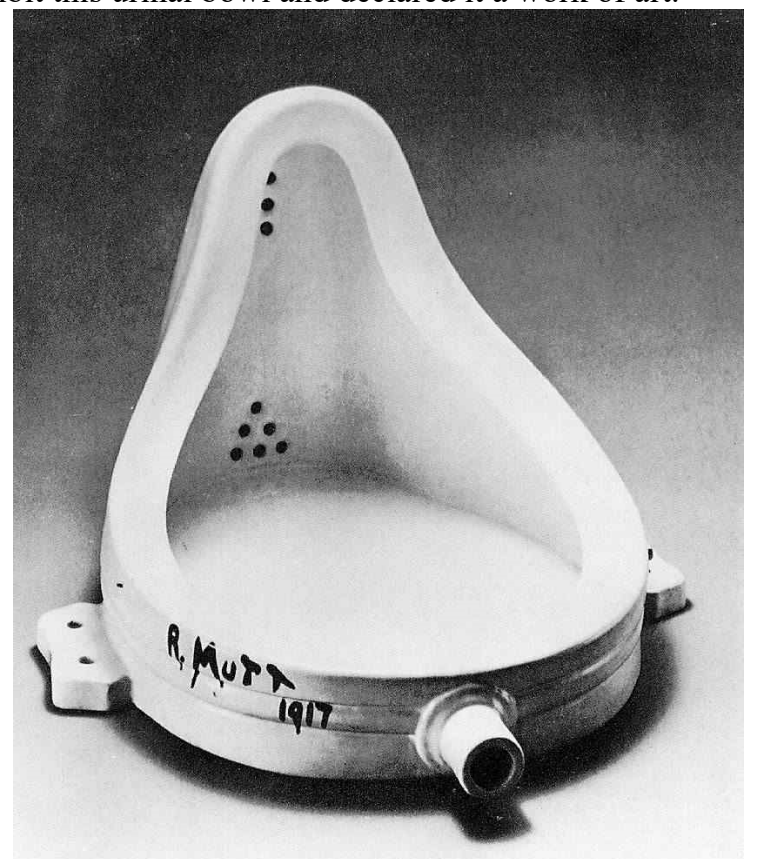

Figure 7: Marcel Duchamp, (fountain) 1917, porcelain (Readymade).

To Duchamp the original readymade have disappeared and replicas remain which " convey the same message as the original". In his view, aesthetic criteria alone is not enough to define what art is and what is not, and it will be the artist who call into question the limits of art by pushing further and further. He will later again assert that ; "stripping the object off its utilitarian status proclaimed by its installation in a museum space, and the new meaning conferred on it by its title, would henceforth suffice to qualify it as a work of art what had not been so a priori." 
This fundamental and innovative approach by Duchamp laid the foundation for a great many interrogation of the status of the narratives in the $20^{\text {th }}$ century, and for a breakthrough of the object into the domain of the plastic art. However this breakthrough of the object since the $20^{\text {th }}$ century is yet to be felt in the spatial art forms in Ghana.

\section{SYMBOLISM AND SCULPTURE}

The choice of using 'Fante' proverbs as the principal reference for this project is informed by the supposition that the Akan topology of which Fante is a part is a rich system of insignia. In most of the Fante communities, conceptual and verbal forms of these insignia have been expressed orally with a greater degree of frequency than the visual. The visual forms, while being present, are comparatively fewer and less diversified. This largely has culminated over the years and informed the apparent predominance and privileging of such cultural matrices as linguistics and musicology in Akan anthropological research practice. Ghana is rich in a variety of ways including natural resources manpower and culture. Within the frame work of culture there is a wide range of heritage including religion, music, dance, art architecture and oral literature. Moreover, in the realm of oral literature we find the immensely rich words of stories, fables, recitation, songs, poetry and proverbs.

In the Ghanaian urban cultural industry, there has been the incorporation and the creolization of 'Fante' and for that matter Akan proverbial concepts and symbolic forms. Unfortunately, the translation of their proverbial concepts into modern Ghanaian spatial, temporal, spatio-temporal and three-dimensional art forms is yet to attract as much curiosity as there has been the documentation of their indigenous sources. A modernist approach in the incorporation of proverb is evident in two analogous but overlapping trend. Firstly, there seem to be a greater consensus around the appropriation of the more secular and already obvious form and content, such as those provided by canoe and 'Asafo' flag decoration and symbolism, body decoration adornment, popular maxims and folk songs. In the second trend however, the more subtle forms and subject matter are made visible through the modern idiom like the use of adinkra symbols in textile designing, paintings Adashie (2002), painting and sculpture Akoi-Jackson (2006), and theatre (Saka Acquaye the lost fisherman). (Jackson 2006).

The experiments in this paper, attempts to transform a person's experience as they engage in the act of interacting with the monument. This new experience offers incentives beyond physical gratification. Each of the experiments in this paper sets to challenge the participants to redefine their own perception of commemorative sculptures based on phenomenology, forcing them accepts an unconventional theme, interact with it, and contemplate their reaction to the experience. The researchers believe commemorative sculptures, which are inspired by proverbs, are a sacred cultural ritual with an intimate connection to each of our lives, thus the experiments in this document attempt to revive this sacred character through re-establishing the importance instilled within the monument when encountered visually or shared with another.

\section{MAIN PROJECT AND DISCUSSIONS}

This document is targeted at not only addressing the issue of over subscription of a particular style of rendition which posits that, that which is true exists only in a timeless world outside tangible reality, \{an idealised 'myth' which stipulated among other things that, not only should commemorative sculptures be figurative and aligned to the rationalized (vertical) axis but it should also be erected on a pedestal as a metaphor for the monuments allusion to the ideal and timeless world. $\}$ The monument was therefore considered not only as finished (or timeless), but also harbouring a single and definite meaning and thus rendered illusionistitcally or frontally (Manu 2008). It also aims at making a case for an alternative which employs the use of ready-mades whose end products do not harbour a single and definite meaning, but thrive on the ideology that meaning is subjective and based on individual experience.

It was intended in this project not to focus on 'Fante' proverbs but to use it as a tool. In as much as they adorn and beautify language they could also inspire in this postmodern era, a visual dialogue.

The first experiment of the project Proverb 1 (figure 8a, b and c) was inspired by the proverb. Owu atwir baakofo nfow) which literally means (Death is inevitable to all). This is a proverb often used during funerals and mostly disliked by 'man' because it reminds you of an inevitable journey that awaits us all. The work is a 28 feet high sculpture work made up of a spine (welded pieces of small round tubes) and the body (square pipes) which have been cut into small rectangular shapes with a length ranging from three to half an inch ( $3 "-1 / 2 ")$. The square pipes were welded to the round pipe one after the other in a seeming endless spiral form evoking a hierarchical physical encounter with movement and a social function which qualifies and specifies the significance of the proverb in question and the spiral in a revealing way bringing to mind how the spiral has been the subject of many artist in history because it incorporated within itself the notion of dialectic progression. The spiral also provided the materialist with identification in their thought with the organic world (plants growth). After evaluating (proverb1), the researchers realized a lack of attention towards the dissolution of the central core (frontality) which was one of my aims, this led to the introduction of colour which was applied in a graded form allowing different colours to fuse into each other gently suggestive of 'life' and the various transitions and transformations that we go through till death. The colour provides the needed diversion for the eye. 


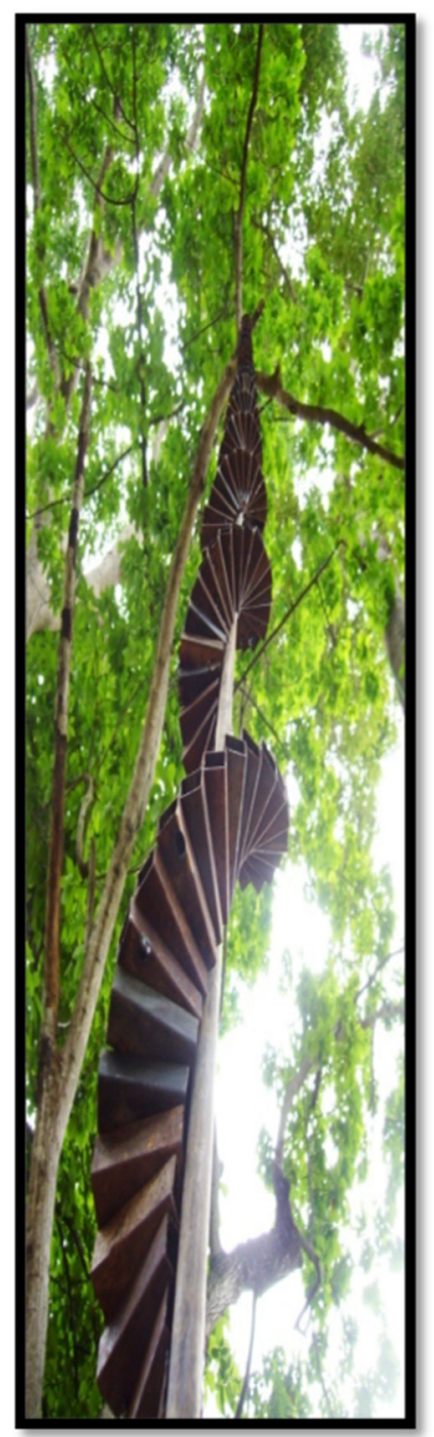

Figure a

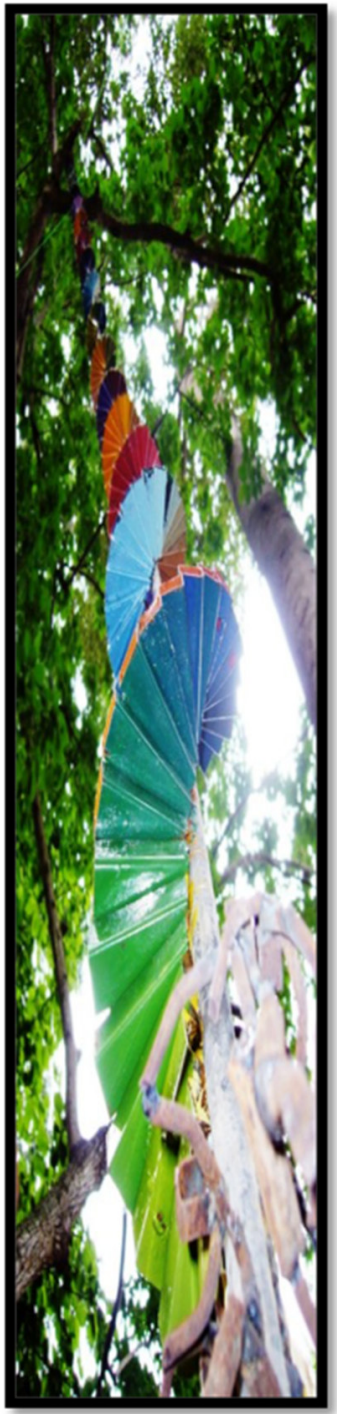

Figure b

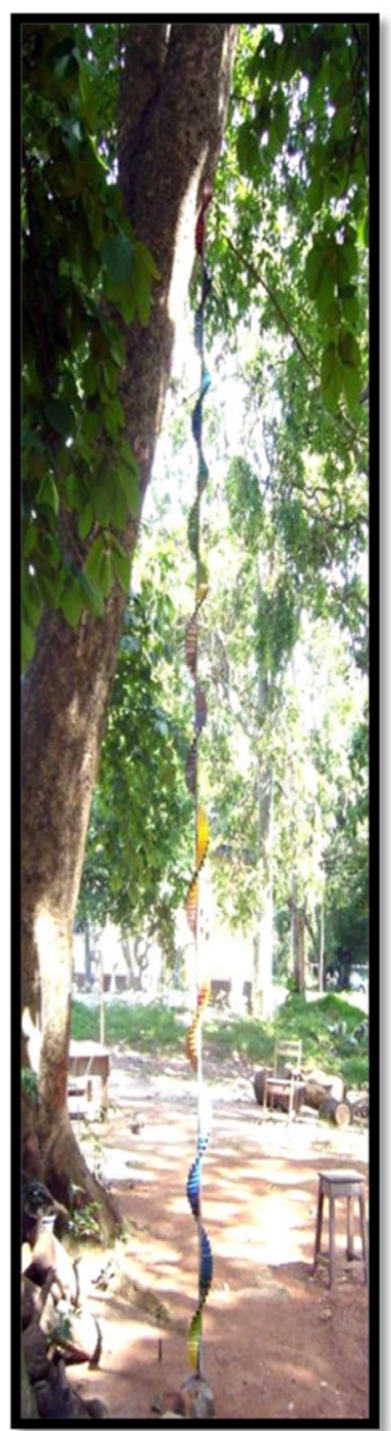

Figure c

Figure 8a, b and c: (Experiment 1)

'Parliament' (fig9a, b and c) which is the title of the last experiment was inspired by the proverb (etsir kur nko agyina) which means (one person cannot go into council). In our traditional set up the seat of governance which is the palace comes with a chief who is the head and his council of elders who always went into consultation whenever they had to pass judgement on an issue or advise the chief. It is this function of the elders which led our forefathers to coin the proverb which has its English version as (two heads are better than one). The experiment is made up of cylindrical 'found' tubes cut into varying lengths and sizes which has been welded together at different angles horizontally and supported vertically with a half inch rod and a base. The various tubes and the inner holes metaphorically represent individuals and their independent views. Looking at the work in general there is this feeling of multiplicity showing even without the introduction of colour. Again there is an organic appeal which greets you at the site of the work. Horizontally, the shape and movement in the work looks like a "Snake" in motion at the same time it is reminiscent of the "Antler" of a male antelope. Pleased with the end results the final study was set in motion. 


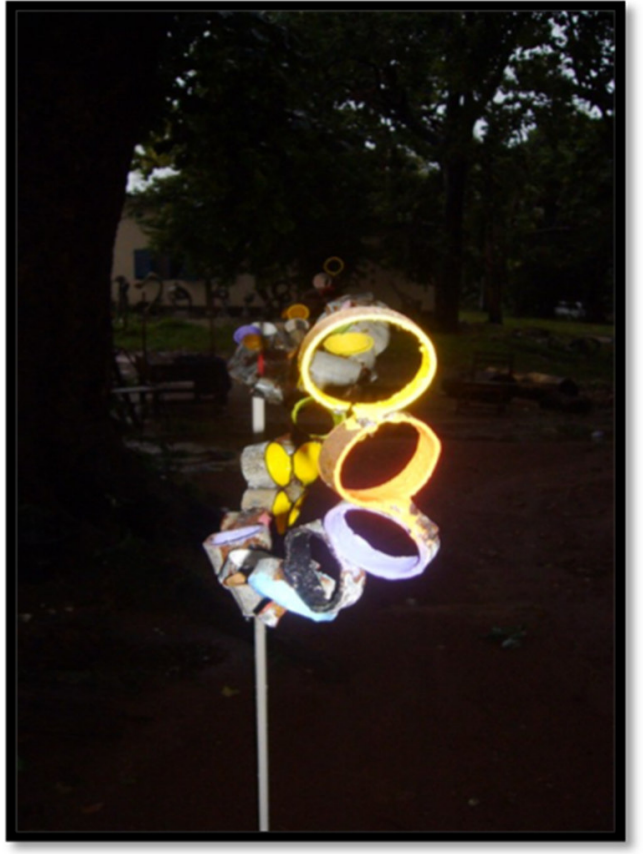

Figure a

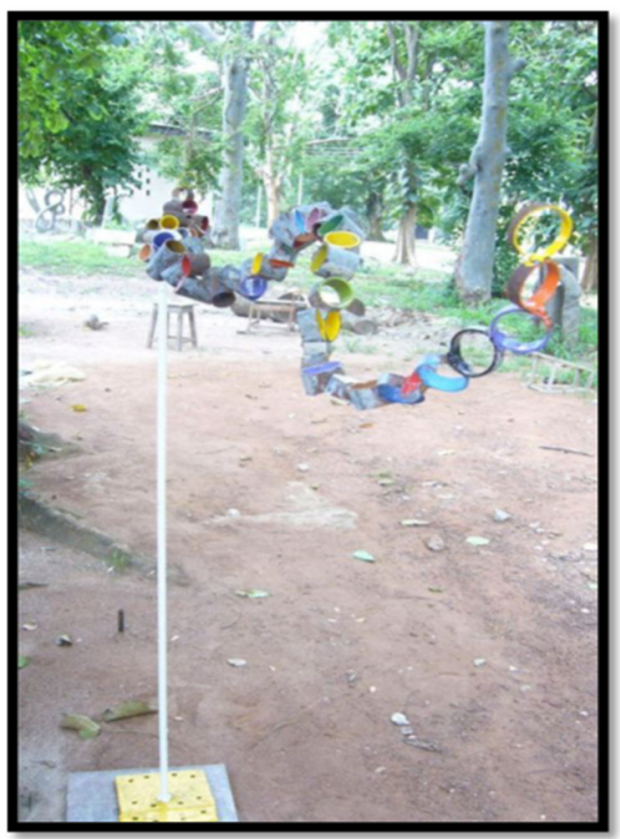

Figure b

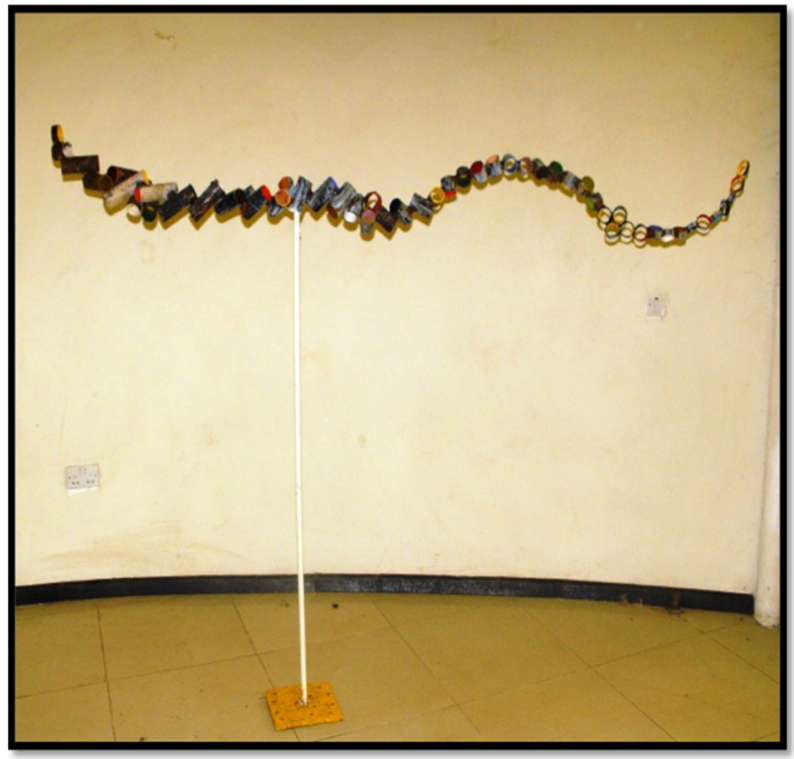

Figure c

Figure 9a, b and c: ( Parliament)

\section{MAIN WORK}

Alluding to the concept of minimalism the study gives an experience of space and time in which one's visual perception cannot be separated from one bodily understanding of its presence. The focus on the entire experience generated by the work is critically articulated in response to the relatively simple cylindrical shapes it is made up of and what Fante proverb it seeks to project. The literal shape of minimalist objects depended on the use of industrial means of production and the creation of objects based on simple geometric forms conceived in advance of their realization. The incorporation of the copy in the creation of works based on repetition or serial forms and the use of fabricated units is a quality, which was read by Rosalind Krauss as a powerful activation of exteriority and the phenomenological unfolding of the viewer's experience in time and space (Buskirk, 2005, p 22-23).

Suggestive of a cross breed of three pole ideologies materialism idealism and minimalism, (fig10a, b, c and d) one is presented with an experience generated and critically articulated by a relatively simple cylindrical objects stuck to each other in a repetitive movement reminiscent of the ideals of minimalism; which has as some of its features, the use of industrial means of production and the creation of objects based on simple geometric forms 
conceived in advance of their realization.

Unlike idealism and minimalism which prides themselves with well refined finished surfaces hinged on the philosophy of being true to the material, the study drifts away from this threshold of 'purity' propagated by modernist conventions, by incorporating the rusty and scratched surfaces of the tubes into the finished work ascribing to the materialist realm of thought which asserts that not only are things in a state of flux but also truth is ascertained through a verified posterior experience. Also there is an arbitrary use of colour and an irrational arrangement of tubes which defeats the idea of a rhythmic arrangement of forms. The poise and counter poise of which are intended to reveal the latent meaning of a composition (Krauss, 1977.p 20). The study also tried as much as possible not to follow colour harmonies and complements so as not to tow the lines of academic canons.

Looking organic in appearance the study tries to impose on the passive on looker an unyielding experience of movement, which is achieved, with the illogical arrangement of tubes and colours, which bestows on the work a lack of transparency. The painted inner part of the individual tubes do not form with each other a relationship that connotes or offer an indication clear to the meaning of the work. Instead, the repetition of the tubes, work to give an allusive feeling. In the end, one must view the study from all sides before one can appreciate it in its entirety unlike the academic style sculpture, which is presented in a single point of reference (front and back).

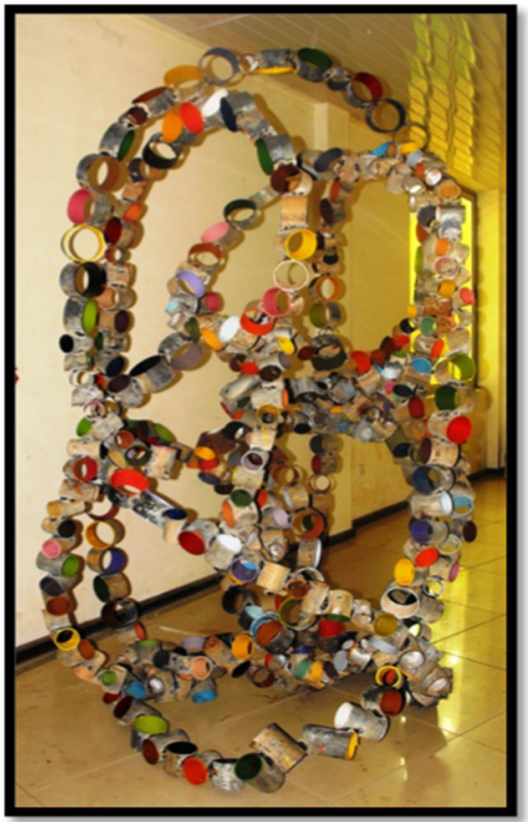

Figure 10a

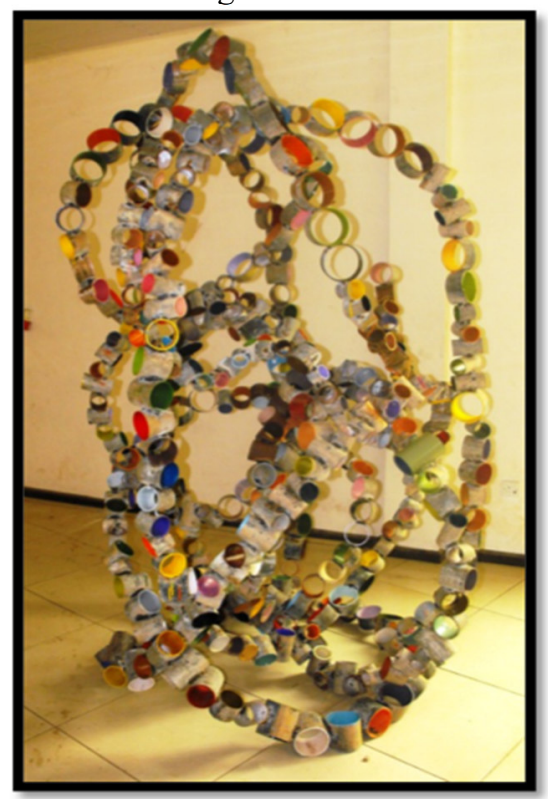

Figure 10c

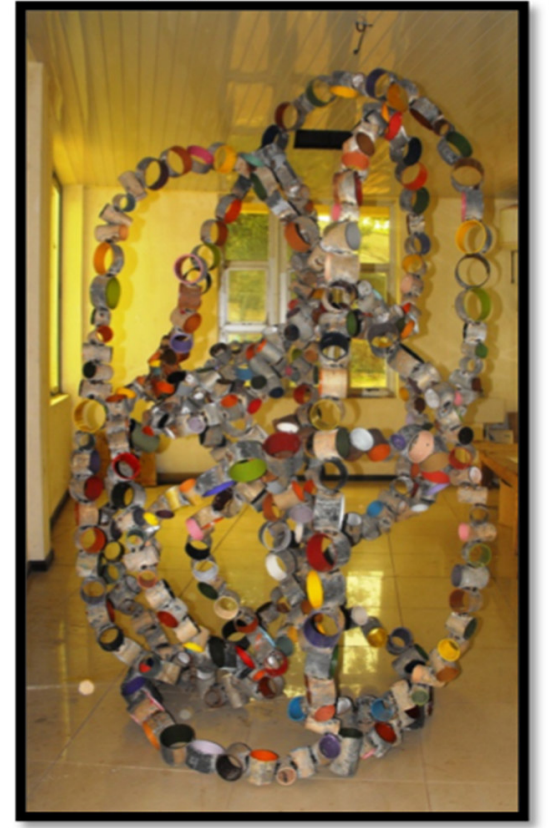

Figure $10 b$

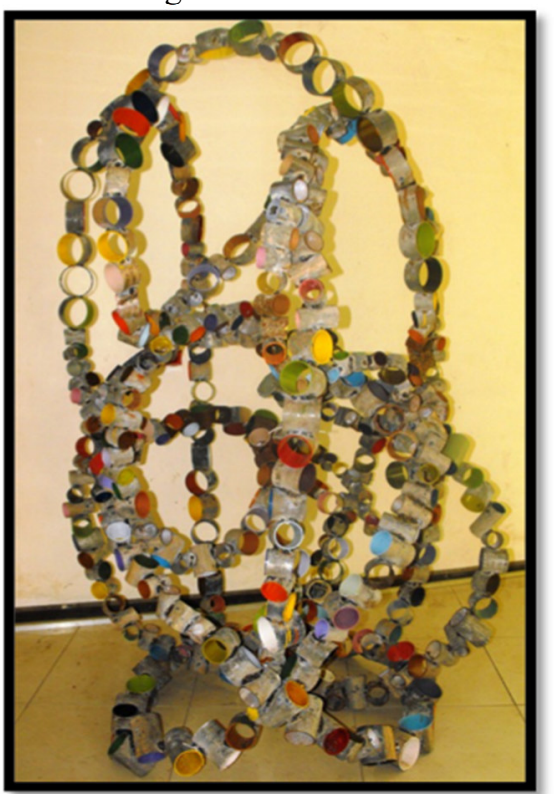

Figure 10d

Figure 10a, b, c, and d. Main project (Untitled) 


\section{EVALUATION}

With the inner part of the study painted (suggesting a finished work) and the outer part left in its organic state (suggesting a work still in progress), the study is left in a paradoxical state incorporating ideas from the idealist and materialist divides. Again, the repetitive nature of arrangement coupled with the use of industrial material (metal pipes) confers on the study the looks of a post minimalist work, given the work a polysemic aura. However, the lack of emphasis on the surface quality alongside the arbitrary introduction of colour defeats the minimalist ideal of absolute uniform application of colour and a concentration on the overall rather than parts.

There is also a reverse in emphasis from arrangement to composition or from whole to parts, which distorts the attempt to give a clear and direct interpretation to the work, which is clearly shown by the multiplicity of parts. Unlike Judd, Morris and Carl Andre (fig11 and fig12) who significantly showed reduction in the number of parts and focused on wholeness of their works, the study from different angles, gives the impression of seeing different works. The difference in the sizes of the tubes shows a kind of relationship which comes across as "regimented changeable units" which "lends themselves to relational structures" because "any part could not replace any other part as is so in Carl Andre's (equivalents). Arrangement here is meant to imply an unprejudiced notion of the whole; which is in consonance with composition, which usually means the adjustment of the parts that is, their size, shape, and colour to arrive at the finished work whose exact nature and meaning is not known beforehand until one has had an encounter with the study?

\section{CONCLUSION}

The objective of this article is to make a case for sculpture works which embody diverse, often antithetical elements. And in bringing these diverse ideologies together in one work, the objective is not to aim at a clatter or conflict or better still a confrontation between extreme ideologies nor for a dialectical answer to them. " the modernist project of purification and giving absolute expression to a single stance by excluding others is a nonstarter and should not be encouraged." (Marien Schouten). On the contrary this document advocates for the promotion of hybridity, consisting of a co-existence and fusion of contrasts.

In this light the dualism this paper seeks to endorse is a dualism which does not encompass an opposition of boundaries that dismisses each other; it is about boundaries that are added to each other . "a relationship not of 'either or' but of 'both"' (Ernst Van Alphen).

Borders and boundaries exist but in our view they should exist almost only as conventions, but possibly never as material entities. Perhaps for the sake of administrative contingencies categorization of ideologies and disciplines may exist however dialogue and dialectic discourses across dualistic divides, should be encouraged and considered as valid and necessary tools needed to help transcend any hostilities that there may be in the visual arts. Moreover, the results of this study seek for not only an interactive discourse but also a relative and polysemic attitude towards the object (sculpture) and the viewer.

In contrast to the modernist ideologies which thrived on compartmentalization and categorization, this paper seeks to present sculpture not as an exclusive discipline which is governed by strict rules and regulations, but a discipline with innumerable avenues of which one could transgress and trespass. A discipline with more opportunities for possibilities. To this effect, this paper presented works which incorporated alongside its conventional materialist trajectory, the post-minimalist model. A move targeted at adding to the quest for a revival of the status quo, which to an appreciable degree has over the years projected sculpture as an immutable discipline.

\section{REFERENCES}

Buskirk M. (2005). The Contingent Object of Contemporary Art. New Ed edition. The MIT Press;

Hal Foster et al (2004) Art Since 1900. (Modernism Antimodernism Postmodernism). 500fifth Avenue, New York: Thame \& Hudson Inc.

Krauss, R. E. (1977). Passages in Modern Sculpture. Cambridge: The MIT Press.

Krauss, R. E. (1971). Terminal Iron Works (The Sculpture of David Smith). Cambridge: The MIT Press.

Krauss, R. E. (1999). The Originality of the Avant-Garde and Other Modernist Myths. Cambridge: The MIT Press. McEvilley, T. (1999) Art and Otherness. New York: McPherson and Company.

Welcker, G C. (1937) Modern Plastic Art. Elements of Reality Volume and Disintegration. Switzerland: Effingerhof A.G. Brugg. 